\title{
Estimation of Time History of I-131 \\ Concentration in Air Using NaI(Tl) Detector Pulse Height Distribution at Monitoring Posts in Fukushima Prefecture
}

\author{
Hideo HIRAYAMA ${ }^{1, *}$, Hiroshi MATSUMURA ${ }^{1}$, \\ Yoshihito NAMITO ${ }^{1}$ and Toshiya SANAMI ${ }^{1}$ \\ ${ }^{1}$ High Energy Accelerator Research Organization, 1-1 Oho, Tsukuba-shi, Ibaraki 305-0801, Japan
}

\begin{abstract}
Time histories of the I-131 concentration in air at monitoring posts in Fukushima Prefecture in March 2011 were estimated using the pulse height distribution of a $\mathrm{NaI}(\mathrm{Tl})$ detector, which was opened to the public. Several corrections to the pulse height distribution were necessary owing to high count rates. The contribution to the count rates from I-131 accumulated around the monitoring post was estimated on the basis of the time history of the peak count rate by the method proposed by the authors. The concentrations of I-131 in air were converted from the peak count rates using the calculated response of the $\mathrm{NaI}(\mathrm{Tl})$ detector with egs 5 for a model of a plume containing I-131 uniformly. The obtained time histories of the I-131 concentration in air at a fixed point in March 2011 were the first ones for Fukushima Prefecture. The results at 3 monitoring posts, Naraha Town Shoukan, Hirono Town Futatunuma and Fukushima City Momijiyama, which can be analyzed during almost all of March, show that a plume including I-131 arrived after March 15. The results at other monitoring posts near Fukushima Daiichi Nuclear Power Plant are used to characterize plume diffusion at the early period of the accident before March 15. The I-131 time-integrated concentrations in air at several monitoring posts were compared with those given in UNSCEAR 2013 ANNEX A, which were obtained using estimated time-dependent rates of release to the atmosphere. The agreement between the two results varies depending on the places compared, owing to the large uncertainties in the estimated release rate used in UNSCEAR. The results obtained in this study can be used to increase the accuracy of the time-dependent release rate estimation.
\end{abstract}

KEYWORDS: iodine 131, concentration in air, time history, Fukushima, Monte Carlo, egs5, NaI scintillator

\section{Introduction}

The time history of the I-131 concentration in air released to the environment resulting from the accident that occurred at the Fukushima Daiichi Nuclear Power Plant (hereinafter referred to as the "1F plant") is important in evaluating the initial internal exposure. In particular,

* Corresponding author, E-mail: hideo.hirayama@kek.jp

DOI : 10.15669 /fukushimainsights.Vol.4.323

(C) 2021 Atomic Energy Society of Japan. All rights reserved.

Originally published in Transactions of the Atomic Energy Society of Japan (ISSN 1347-2879), Vol. 14, No. 1, p.1-11 (2015)

in Japanese. (Japanese version accepted: October 14, 2014) 
insufficient data were obtained in Fukushima Prefecture during the early stage of the accident, a period that needs to be evaluated. An attempt needs to be made to estimate the time variation in I-131 emissions using various data such as dose rate information including the air absorbed dose rate and ambient dose equivalent rate (for which there is an abundance of measurement data) and the I-131 concentration deposited on the ground surface. These data can serve as the basis for the estimation of the concentration in air. Although the time history of dose rate is important information to determine the arrival of a plume, the analysis of the monitoring post data conducted by the Nuclear Science Research Institute (NSRI) of the Japan Atomic Energy Agency (JAEA) showed that the changes in the dose rate do not correspond to the changes in the I-131 concentration in air ${ }^{1)}$. In addition, because the density of I-131 deposited on the ground is an integral value accompanying several plume arrivals, and it is extremely difficult to obtain the time history of the I-131 emission from these data. However, if a $\mathrm{NaI}(\mathrm{Tl})$ detector was used in the dose measurement at monitoring posts, pulse height distribution data may be available. In this case, it is possible to obtain data on the radionuclides in the air from the pulse height distribution. Fukushima Prefecture publicly disclosed the numeric data of the pulse height distribution obtained at the monitoring posts in March 2011 on a website ${ }^{2}$.

Applying a following method proposed by authors for the open data of Fukushima Prefecture to estimate the concentration of I-131 in air at monitoring posts aftermath of the accident in March. The method is that estimates the contribution of radionuclides deposited on the surroundings separately from the contribution of radionuclides contained in air, from the time histories of gamma ray total absorption peak count rates ${ }^{1}$. Concerning three monitoring posts (Syoukan in Naraha Town, Futatunuma in Hirono Town, and Momijiyama in Fukushima City) at which analyzable data were obtained for the whole of March, we estimated the time history of the I-131 concentration in air at locations in Fukushima Prefecture located far away from the $1 \mathrm{~F}$ plant during this month. However, at most of the monitoring posts near the $1 \mathrm{~F}$ plant, not only were data obtained only until the middle of March but it also was impossible to perform peak analysis based on the pulse height distribution because of the pulse pile-up on and after March 15 even if data were available. Therefore, only the time history of concentration in air before March 15 was estimated.

Using the time history of the concentration in air obtained, we determined the time integration I-131 concentration in air to compare it to the estimated value described in UNSCEAR 2013 ANNEXA $^{3)}$.

\section{Values Measured at Monitoring Posts}

\section{Disclosed Pulse Height Distribution Data Obtained at Monitoring Posts}

Fukushima Prefecture disclosed the pulse height distribution data obtained for $10 \mathrm{~min}$ and $1 \mathrm{~h}$ using $\mathrm{NaI}(\mathrm{Tl})$ detectors at 13 monitoring posts as shown in Table $\mathbf{1}^{2}$. The directions and distances from the $1 \mathrm{~F}$ plant described in the table are quoted from the website ${ }^{4)}$ a . The $\mathrm{NaI}(\mathrm{Tl})$ detectors used were $\phi 2^{\prime \prime} \times 2^{\prime \prime}$ in size and placed at a height of $3 \mathrm{~m}$ above the ground surface. Among the 13 locations, Kamihatori in Futaba Town was excluded from the concentration estimation shown because only the data obtained until 11:00 p.m. on March 12 were available and the count rates were too high to perform peak analysis at and after 8:00 on that day. The data

\footnotetext{
${ }^{a}$ Because Momijiyama in Fukushima City was not included in the monitoring posts described on the website, we estimated it from the address.
} 
Table 1 Monitoring posts information made publicly available by Fukushima Prefecture

\begin{tabular}{|c|c|c|c|c|c|}
\hline $\begin{array}{c}\text { Name of city or } \\
\text { town }\end{array}$ & Name of post & $\begin{array}{l}\text { Distance from } \\
\text { Fukushima } \\
\text { Daiichi Nuclear } \\
\text { Power Plant }\end{array}$ & $\begin{array}{l}\text { Data collection } \\
\text { period during } \\
\text { March } 2011\end{array}$ & $\begin{array}{c}\text { Analyzable data } \\
\text { period }\end{array}$ & $\begin{array}{c}\text { Measurement } \\
\text { duration } \\
\text { (minutes) }\end{array}$ \\
\hline \multirow{3}{*}{ Futaba-town } & Koriyama & NNW 2.8 km & till 14th $24: 00$ & till 14th 20:00 & 10 \\
\hline & Yamada & WNW $4.1 \mathrm{~km}$ & till 31th $24: 00$ & till 15th 11:00 & 60 \\
\hline & Kamihatori & NW5.6 km & till 12th $24: 00$ & & 60 \\
\hline \multirow{4}{*}{ Okuma-town } & Mukaihata & $\mathrm{SW} 4.0 \mathrm{~km}$ & till 15 th $2: 00$ & till 14th 20:00 & 60 \\
\hline & Oono & WSW $4.9 \mathrm{~km}$ & till 16th $16: 00$ & till 14th 21:00 & 60 \\
\hline & Minamidai & $\mathrm{SW} 2.4 \mathrm{~km}$ & till 14th 20:00 & till 14th 20:00 & 60 \\
\hline & Ottozawa & SSW $1.6 \mathrm{~km}$ & till 15 th $7: 00$ & till 14th 19:00 & 60 \\
\hline \multirow{2}{*}{ Naraha-town } & Shoukan & $\mathrm{SSW} 14.2 \mathrm{~km}$ & till 31th $24: 00$ & till 31th 24:00 & 60 \\
\hline & Shigeoka & SSW $14.2 \mathrm{~km}$ & till 14th 24:00 & till 14th 22:20 & 10 \\
\hline \multirow{2}{*}{ Tomioka-town } & Simokoriyama & SSW $11.8 \mathrm{~km}$ & till 15th 8:00 & till 14th 21:00 & 60 \\
\hline & Tomioka & SSW $9.4 \mathrm{~km}$ & till 13th 24:00 & till 13th 24:00 & 10 \\
\hline Hirono-town & Futatunuma & $\mathrm{S} 21.4 \mathrm{~km}$ & till 31th 24:00 & till 31th 24:00 & 60 \\
\hline Fukushima-city & Momijiyama & NW $61.3 \mathrm{~km}$ & till 28th $18: 00$ & till 28th $18: 00$ & 60 \\
\hline
\end{tabular}

enabling peak analysis were obtained for the whole of March at Shoukan in Naraha Town and Futatunuma in Hirono Town and until March 28 at Momijiyama in Fukushima City. However, at the other monitoring posts, no data were available on and after March 15 or the count rates were too high to perform peak analysis even if the data were available. Therefore, we used the data obtained there to study the time variation in the I-131 concentration in air in the areas around the $1 \mathrm{~F}$ plant before a drastic increase occurred at midnight on March $14^{\mathrm{b}}$.

\section{Correction of Pulse Height Distribution Data}

\section{(1) Correction of digit overflow}

Most of the pulse height distribution data are disclosed as the integration values of $1 \mathrm{~h}$. Because the count values of the respective channels are displayed in six digits, when a count value becomes a number with six or more digits, only the upper six digits are shown. As an example, Figure 1 shows the pulse height distribution obtained at 2:00-3:00 p.m. on March 13 at Minamidai in Okuma Town. It is apparent that the disclosed data of the 4-45 channels caused digit overflow. The data of the 12-18 channels were centupled $(\times 100)$ and other data causing digit overflow were decoupled $(\times 10)$ to obtain the corrected result. Taking this step enabled us to obtain a normal pulse height distribution. Based on this result, we conducted the same consideration for all the pulse height distribution data and corrected the data by centupling and decoupling the digit overflow (digit overflow correction).

\section{(2) Correction of live time}

In the case where the measurement data indicated a high dose rate, it is highly likely that there was a difference between the live time, which is the net measurement time, and real time, which is the real measurement time. In the data obtained at Koriyama in Futaba Town at 10-min intervals, both the live time and real time are shown. Figure 2 shows the relation between the total count value of the pulse height distribution (cps) and (live time) / (real time). As shown in

\footnotetext{
${ }^{\mathrm{b}}$ Although the data obtained at Tomioka in Tomioka Town were only available until March 13, no I-131 was detected during that period. Therefore, we determined that no plume had arrived by March 13 and we used this information.
} 


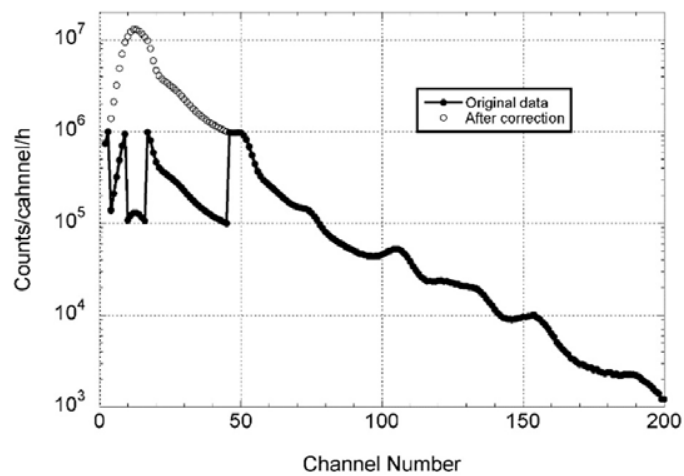

Figure 1 Pulse height distribution of $\mathrm{NaI}(\mathrm{Tl})$ detector at Okuma Town Minamidai at 14:00 15:00 March 13, 2011

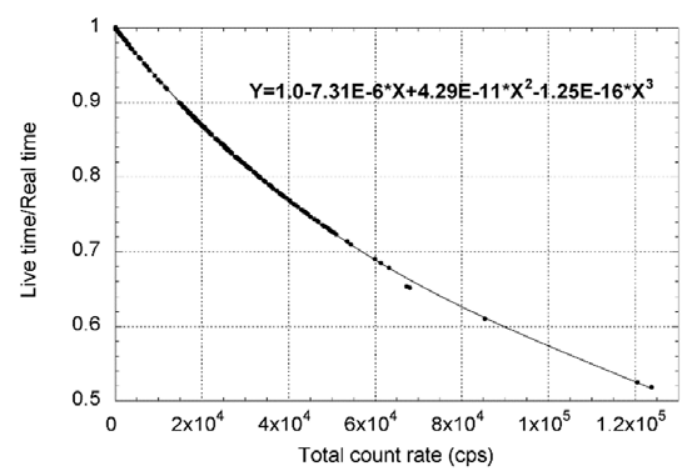

Figure 2 Relation between total count rate (cps) and (live time)/(real time) obtained from pulse-height distribution data at Futaba Town Koriyama

the figure, the relation between the two can be approximated using the following polynomial equation:

$$
\frac{\text { live time }}{\text { real time }}=1.00-7.31 \times 10^{-6} \times c+4.29 \times 10^{-11} \times c^{2}-1.25 \times 10^{-16} \times c^{3}
$$

where $c$ is the count value per second obtained by integrating a pulse height distribution. Although both live time and real time are 3,600 s in terms of hourly data, it was determined from the data obtained at 10-min intervals that the live time of 3,600 s was incorrect. As a result, all data were corrected using the value of (live time) / (real time) obtained using equation (1) (live time correction).

\section{(3) Check of correction result}

To confirm the effectiveness of "digit overflow correction" and "live time correction," we compared the total count rates of the pulse height distribution after completing both corrections using the air absorbed dose rate disclosed on Fukushima Prefecture's website. Figure 3 shows the comparison result in the case of Minamidai in Okuma Town. The low-level air absorbed dose rates were measured using $\mathrm{NaI}(\mathrm{Tl})$ detectors and the high-level air absorbed dose rates were measured using ionization chambers. At $100 \mathrm{nGy} / \mathrm{h}$ and higher, the low and high dose rate values were the same. Therefore, it would appear that the dose rate data obtained using a 
$\mathrm{NaI}(\mathrm{Tl})$ detector for the measurement of low dose rates showed normal values even in the high dose rate range. Because the corrected count rates showed the same time history as both air absorbed dose rates, we can state that we could confirm the appropriateness of the aforementioned two corrections.

\section{Peak Count Rates of I-131}

Using the corrected pulse height distribution data obtained using a $\mathrm{NaI}(\mathrm{Tl})$ detector, we determined the net count rates corresponding to the total absorption peak of I-131 with 365 $\mathrm{keV}$ as the peak count rate. The number of counts of the background components of the peak were approximated by the area of a trapezoid created by connecting the counts on both sides of the peak and then the net count rate was deduced by subtracting the background counts from the entire peak counts. The error includes the statistical error deriving from only the peak count. Figure 4 shows the time history of the peak count rates and air absorbed dose rates obtained at Koriyama in Futaba Town. As the figure shows, when the air absorbed dose rate significantly increased, the peak count rates of I-131 decreased abnormally. Figure 5 shows the pulse height distributions obtained at Koriyama in Futaba Town between 4:00 and 5:00 as well as 8:00 and 9:00 on March 12. Based on the time history of the air absorbed dose rate, the plumes arrived at approximately 4:30 and 8:10. Because there was no peak of I-131 in the pulse

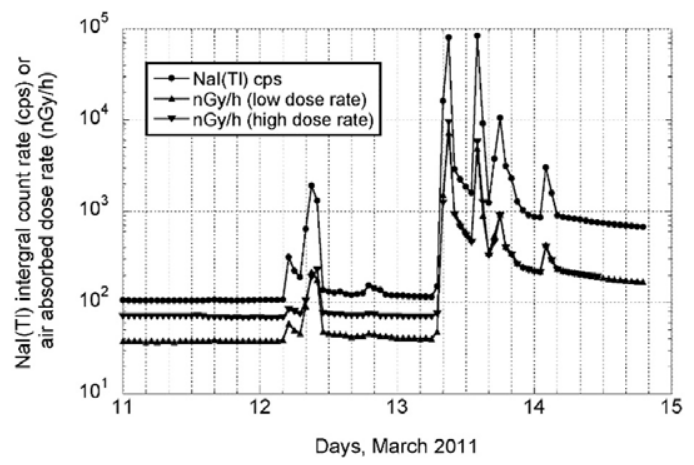

Figure 3 Comparison between corrected total count rates and air absorbed dose rates at Okuma Town Minamidai

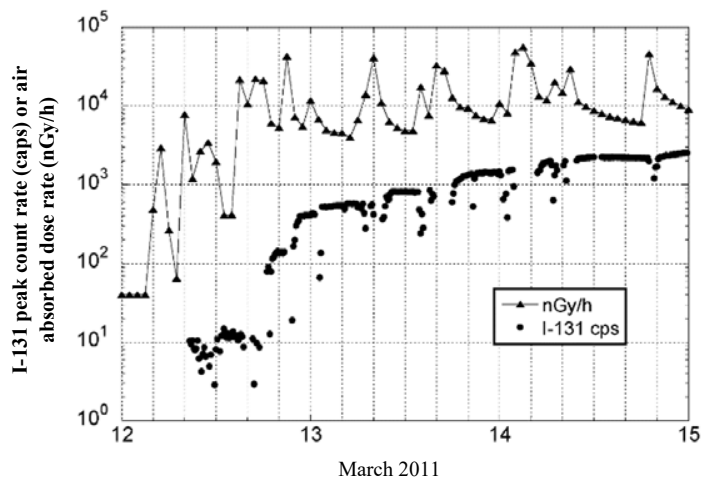

Figure 4 Comparison of time histories between I-131 peak count rates and air absorbed dose rates at Futaba Town Koriyama 


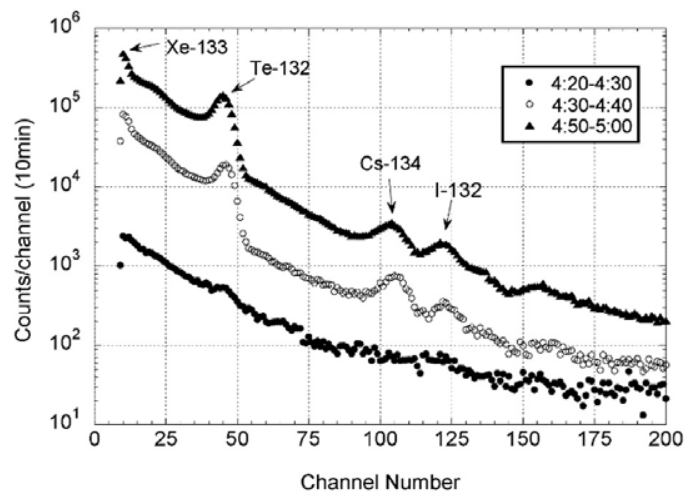

(a) 4:20-4:30, 4:30-4:40 and 4:50-5:00

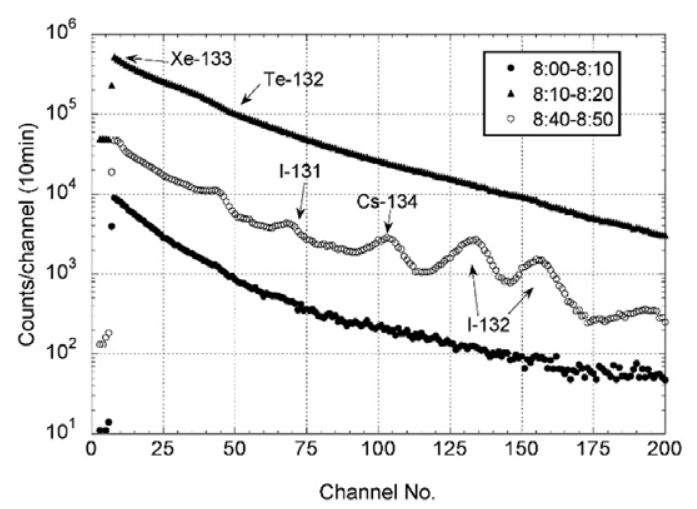

(b) $8: 00-8: 10,8: 10-8: 20$ and $8: 40-8: 50$

Figure 5 Pulse height distribution of $\mathrm{NaI}(\mathrm{Tl})$ detector at Futaba Town Koriyama in March 12

(a) 4:20-4:30, 4:30-4:40 and 4:50-5:00

(b) $8: 00-8: 10,8: 10-8: 20$ and $8: 40-8: 50$

height distributions during these periods and Xe-133 as well as Te-132 increased significantly, the dose rates increased because of these nuclides. If I-131 was contained in the plumes that arrived, a deposition proportional to the concentration in the plumes occurred to increase the peak count rates, as seen in the time series variation in the peak count rates of I-131 in Figure 4. However, after the plume at approximately 4:30 passed, the pulse height distribution returned to a state close to normal at 8:00 in which no peak of radionuclides was detected.

This indicates that the plume contained minimal I-131. The peak of I-131 became clear after $8: 40$. In this manner, it is known that the increase in the I-131 concentration in air because of the arrival of plume had a tendency to be later than that of Xe-133 and Te-132. A more significant increase in the concentrations of Xe-133 and Te-132 than that of I-131 affected the calculation of the I-131 peak area and resulted in an abnormal situation where it became smaller than the peak count rates based on I-131, which was deposited before the plumes arrived. In addition, if there were some time slots during which peak analysis could not be performed during the early stage of an increase in the concentration because of the arrival of a plume, the information obtained during that period was reflected in the I-131 peak count rate later. Given this, we interpolated the data to facilitate a smooth variation in the previous and subsequent count rates, for the time slots during which the peak count rates decreased abnormally after the dose rates increased rapidly and the time periods during which the count rates were too high 
to calculate the peak count rate. Figure 6 shows the time history of the I-131 peak count rates after data interpolation. The same data interpolation was applied to other monitoring posts to estimate the I-131 concentration in air. Figure 7 shows the time history of the I-131 peak count rates after correction observed at Syoukan in Naraha Town and Futatunuma in Hirono Town until 24:00 on March 31 as well as at Momijiyama in Fukushima City until 18:00 on March 28. This figure also shows the I-131 decay curve. Concerning the plume observed on March 16 at Shoukan in Naraha Town, the reduction rate of peak count rate after the plume passed was slightly less than decay of I-131. During the pulse height analysis at the maximum peak count rate, it is possible that the contribution of other nuclides was large and the I-131 peak count rates were underestimated.

It was not only demonstrated in the results of the measurements obtained at a number of expressways in Fukushima Prefecture using $\mathrm{LaBr}_{3}$ on March 15 by Matsumura, et al ${ }^{5}$. but also observed in the analysis at the monitoring posts of the NSRI described in reference 1 that the composition of nuclides contained in the plumes varied depending on the place and time of measurement. The form of the pulse height distribution was also confirmed to vary among the pulse height distributions observed at the monitoring posts used in this study. Figure 8 shows a comparison between Oono in Okuma Town on March 13 and Momijiyama in Fukushima City on March 15 as a typical example. At Oono in Okuma Town, it was found that the radionuclides

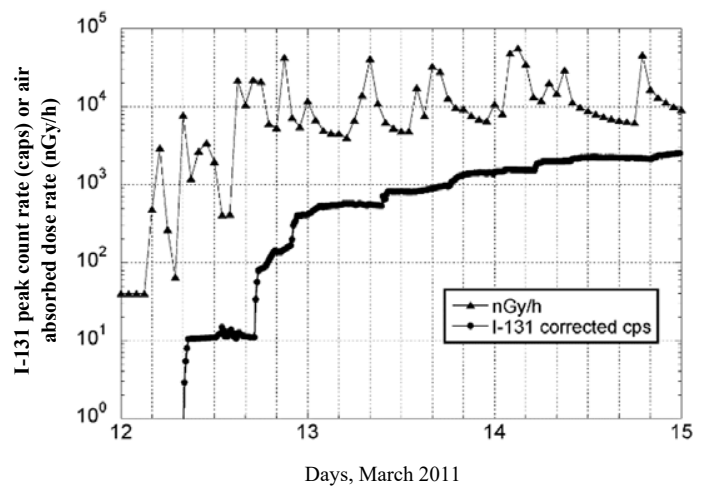

Figure 6 Comparison of time histories between corrected I-131 peak count rates and air absorbed dose rates at Futaba Town Koriyama

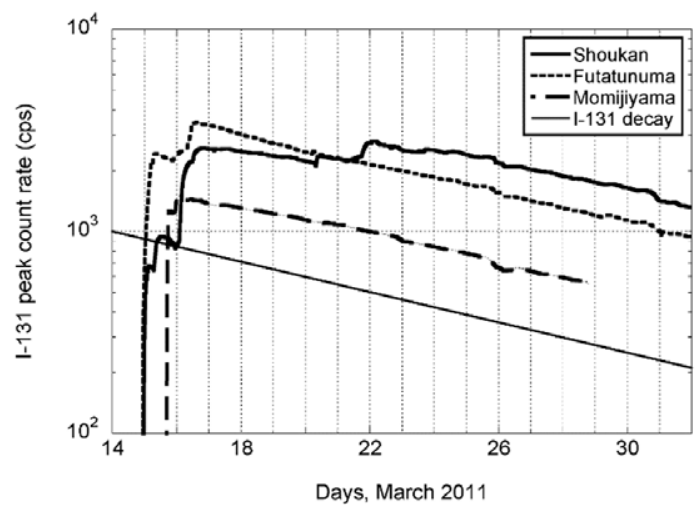

Figure 7 Time histories of corrected peak count rates at Naraha Town Shoukan, Hirono Town Futatunuma and Fukushima City Momijiyama 


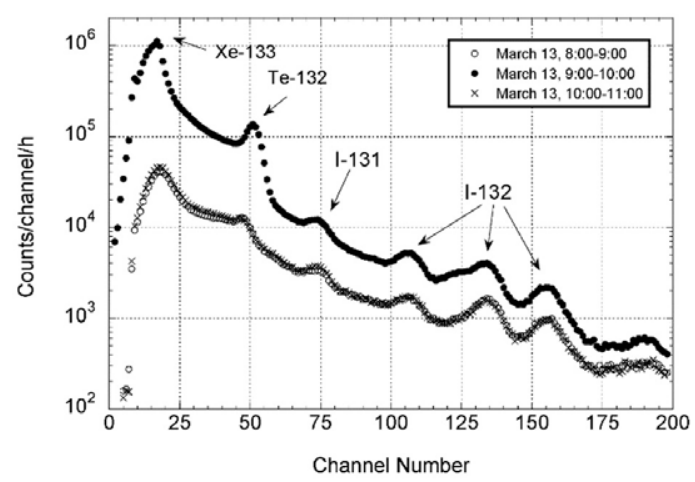

(a) Okuma-town Oono

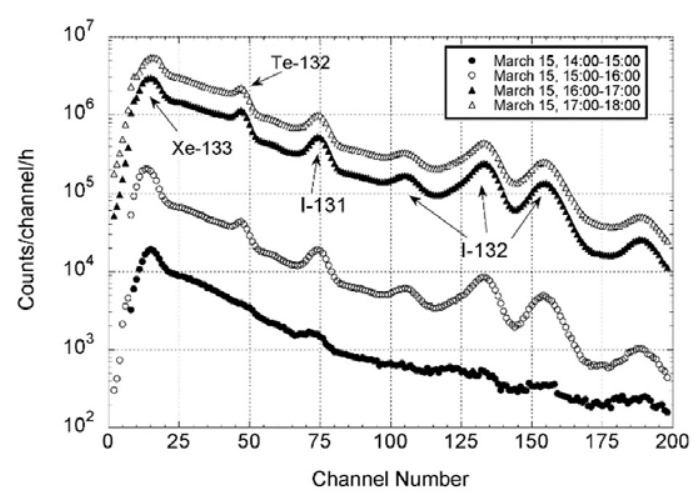

(b) Fukushima-city Momijiyama

Figure 8 Comparison of pulse height distributions of $\mathrm{NaI}(\mathrm{Tl}$ ) detector at Okuma Town Oono (March 13) and Fukushima City Momijiyama (March 15)

(a)Okuma Town Oono, (b)Fukushima City Momijiyama

in the plumes that arrived between 9:00 and 10:00 mostly consisted of Xe-133, Te-132, and I-132, which is a progeny nuclide of Te-132, and the percentage of I-131 was very low. However, at Momijiyama in Fukushima City, I-131 increased at the same rate as Xe-133 and Te-132. The variation in the nuclide composition depending on the location and time of measurement is an important matter that needs to be considered when estimating the release amounts using air absorbed dose and $1-\mathrm{cm}$ dose equivalent rates.

\section{Estimation of the Time History of the I-131 Concentration in Air}

\section{Time History of the Peak Count Rates Caused by the I-131 in the Arrived Plumes}

In the same manner as described in reference 1 for the time history of the peak count rates corresponding to $365 \mathrm{keV}$ of the respective monitoring posts, we determined the time of measurement when an increase in a count rate was observed as the plume start time and the time of the completion of measurement which was started from the moment when the count rate 
Table 2 Start and stop time of plume identified at monitoring posts in Futaba Town and Okuma Town together with average and time-integrated concentrations of I-131 in air

\begin{tabular}{|c|c|c|c|c|}
\hline Monitoring post & $\begin{array}{c}\text { Start time } \\
\text { (dd } \mathrm{hh}: \mathrm{mm})\end{array}$ & $\begin{array}{c}\text { Stop time } \\
(\mathrm{dd} \mathrm{hh}: \mathrm{mm})\end{array}$ & $\begin{array}{l}\text { Average } \\
\left(\mathrm{Bq} / \mathrm{m}^{3}\right)\end{array}$ & $\begin{array}{l}\text { Time-integrated } \\
\left(\mathrm{Bq} \mathrm{h} / \mathrm{m}^{3}\right)\end{array}$ \\
\hline \multirow{2}{*}{ Futaba-town Yamada } & $12^{\text {th }} 8: 00$ & $12^{\text {th }} 22: 00$ & 290 & 4,050 \\
\hline & $13^{\text {th }} 7: 00$ & $14^{\text {th }} 0: 00$ & 681 & 11,600 \\
\hline \multirow{4}{*}{ Futaba-town Koriyama } & $12^{\text {th }} 7: 00$ & $12^{\text {th }} 14: 00$ & 47.4 & 379 \\
\hline & $12^{\text {th }} 16: 00$ & $13^{\text {th }} 7: 00$ & 1,340 & 21,500 \\
\hline & $13^{\text {th }} 8: 00$ & $13^{\text {th }} 11: 00$ & 1,100 & 4,390 \\
\hline & $13^{\text {th }} 14: 00$ & $14^{\text {th }} 13: 00$ & 1,660 & 39,800 \\
\hline Okuma-town Mukaihata & $13^{\text {th }} 7: 00$ & $13^{\text {th }} 20: 00$ & 66.7 & 867 \\
\hline \multirow{3}{*}{ Okuma-town Oono } & $12^{\text {th }} 12: 00$ & $13^{\text {th }} 3: 00$ & 8.09 & 212 \\
\hline & $13^{\text {th }} 7: 00$ & $13^{\text {th }} 20: 00$ & 350 & 4,550 \\
\hline & $14^{\text {th }} 7: 00$ & $14^{\text {th }} 21: 00$ & 33.9 & 373 \\
\hline \multirow{2}{*}{ Okuma-town Minamidai } & $12^{\text {th }} 4: 00$ & $12^{\text {th }} 16: 00$ & 3.33 & 39.9 \\
\hline & $13^{\text {th }} 1: 00$ & $13^{\text {th }} 23: 00$ & 335 & 7,030 \\
\hline \multirow{3}{*}{ Okuma-town Ottozawa } & $12^{\text {th }} 2: 00$ & $12^{\text {th }} 15: 00$ & 9.47 & 123 \\
\hline & $13^{\text {th }} 6: 00$ & $13^{\text {th }} 15: 00$ & 906 & 8,150 \\
\hline & $14^{\text {th }} 0: 00$ & $14^{\text {th }} 7: 00$ & 136 & 949 \\
\hline
\end{tabular}

a) Average concentration in air.
b) Time-intergrated concentration in air.

Table 3 Start and stop time of plume identified at monitoring posts in Naraha Town Shoukan, Hirono Town Futatunuma and Fukushima City Momijiyama together with average and time-integrated concentrations of I-131 in air

\begin{tabular}{ccccc}
\hline Monitoring post & $\begin{array}{c}\text { Start time } \\
(\mathrm{dd} \mathrm{hh}: \mathrm{mm})\end{array}$ & $\begin{array}{c}\text { Stop time } \\
(\mathrm{dd} \mathrm{hh}: \mathrm{mm})\end{array}$ & $\begin{array}{c}\text { Average } \\
\left(\mathrm{Bq} / \mathrm{m}^{3}\right)\end{array}$ & $\begin{array}{c}\text { Time-integrated } \\
\left(\mathrm{Bq} \mathrm{h} / \mathrm{m}^{3}\right)\end{array}$ \\
\hline \multirow{2}{*}{ Naraha-town Shoukan } & $14^{\text {th }} 21: 00$ & $15^{\text {th }} 16: 00$ & 1,800 & 34,200 \\
\cline { 2 - 5 } & $15^{\text {th }} 22: 00$ & $16^{\text {th }} 20: 00$ & 1,680 & 37,100 \\
\cline { 2 - 5 } & $20^{\text {th }} 7: 00$ & $20^{\text {th }} 15: 00$ & 1,060 & 4,440 \\
\hline \multirow{2}{*}{ Hirono-town Futatunuma } & $21^{\text {th }} 15: 00$ & $22^{\text {th }} 7: 00$ & 4,080 & 65,300 \\
\cline { 2 - 5 } & $14^{\text {th }} 21: 00$ & $15^{\text {th }} 12: 00$ & 5,100 & 76,500 \\
\hline Fukushima-city Momijiyama & $15^{\text {th }} 21: 00$ & $16^{\text {th }} 20: 00$ & 2,930 & 67,400 \\
\hline
\end{tabular}

a) Average concentration in air.

b) Time-integrated concentration in air.

stopped increasing and started to attenuate according to the decay of I-131 half-life as the plume stop time. In the case of Koriyama in Futaba Town, data obtained every 10 min were available, but a large amount of data was required for the correction of peak count rates. Therefore, we used the hourly-averaged peak count rates for the analysis. Tables $\mathbf{2}$ and $\mathbf{3}$ show the estimated plume start and stop times based on this concept.

The time history of the I-131 peak count rates in the plumes were determined using the estimation method based on the time history of the peak count rates suggested in reference 1 .

\section{Peak Detection Efficiency of NaI(Tl) Detectors for $365-\mathrm{keV} \gamma$ ray of I-131 in the Plumes}

In the same manner as described in reference 1, we calculated the photon spectra of the respective angle sections which enter a detector placed at a height of $3 \mathrm{~m}$ above the ground 
surface in the air of the NTP state $\left(20^{\circ} \mathrm{C}, 1 \mathrm{~atm}\right)$, by applying the method of replacing the gamma-ray flux from a plane isotropic source with a point isotropic source and plane detector ${ }^{6}$ to egs $5^{7}$, based on the assumption that I-131 is infinitely present in a horizontal direction and from the ground surface to the plume height in a vertical direction at a uniform concentration. We calculated the peak detection efficiency using egs 5 assuming that the photons with spectra of the respective angle sections obtained enter the detector at corresponding angles. Because the lower structure of the detector and the structure of the monitoring post contribute to scattered radiation but have a minimal impact on un-scattered photons that may cause a total absorption peak, we considered only the aluminum cover of the $\mathrm{NaI}(\mathrm{Tl})$ detector and the $\mathrm{NaI}(\mathrm{Tl})$ detector in the calculation of the peak detection efficiency. For the peak detection efficiencies corresponding to $365-\mathrm{keV}$ gamma radiation of I-131, we obtained $0.0524,0.0574$, and 0.0585 cps per $\mathrm{Bq} / \mathrm{m}^{3}$ for heights of $100 \mathrm{~m}, 200 \mathrm{~m}$, and $300 \mathrm{~m}$, respectively.

Although the plume heights are within the range between $100 \mathrm{~m}$ and 1,000 m, considering that the difference resulting from plume height is small and the distance from the $1 \mathrm{~F}$ plant is short, we used the peak detection efficiency in the case of a plume height of $100 \mathrm{~m}$ in which the concentration is the highest for the same count rate as the factor for converting the peak count rate based on the I- 131 concentration in air. If this conversion factor is used, an overestimation of approximately $10 \%$ occurs when the plume height is $300 \mathrm{~m}$.

\section{Result and Discussion}

\section{I-131 Concentration in Air on or before March 15}

Using the peak count rates based on the I-131 in the plumes that arrived as well as the conversion factor obtained using the method described in Chapter III, we determined the time history of the I-131 concentration in air during the period prior to a drastic increase that occurred at midnight on March 14. Figure 9 shows the results obtained at the monitoring posts at Koriyama in Futaba Town, Yamada in Futaba Town, Mukaihata in Okuma Town, Oono in Okuma Town, Minamidai in Okuma Town and Ottozawa in Okuma Town on March 12, 13, and 14. At the monitoring posts in Naraha Town, Tomioka Town, Hirono Town and Fukushima City, an increase in the concentration in air was not observed during this period.

On March 12, at the monitoring posts at Koriyama and Yamada in Futaba Town on the north side of the $1 \mathrm{~F}$ plant, a relatively high I-131 concentration was observed although the concentration and time variation were different between them. However, at the monitoring posts in Okuma Town south of the 1F plant, I-131 was not detected or detected as a very small amount. The result corresponded to the estimation based on the weather information that the I-131 emitted on March 12 spread mainly to the north. On March 13, an increase in the concentration occurred because of the arrival of plumes at all monitoring posts although the time and the concentration in air differed. On March 14, the same level of increase as that of March 13 was observed at Koriyama in Futaba Town. Although a slight increase was also observed at Ottozawa and Oono in Okuma Town, an increase resulting from the arrival of plumes was not observed at the other monitoring posts. At midnight on March 14, the count rates recorded at many monitoring posts increased significantly and it became impossible to conduct peak analysis. The final time at which data could be analyzed shown in Table 1 corresponds to the time of the arrival of a high-concentration plume. While an increase at the monitoring posts around the 1F plant including Shoukan in Naraha Town and Futatunuma in Hirono Town began at 20:00 or 21:00 on March 14, no increase was observed by 24:00 on March 14 at Koriyama in Futaba 


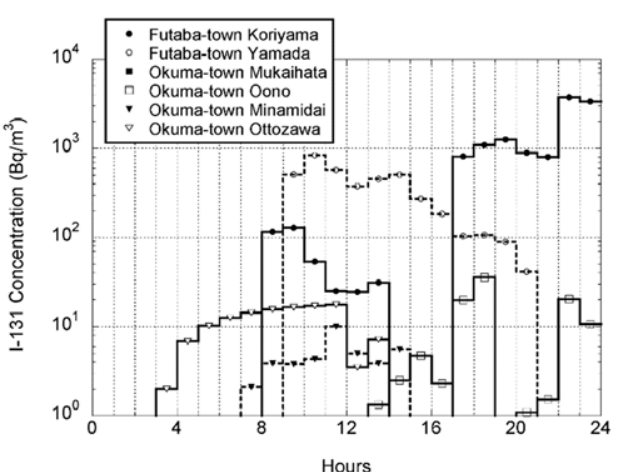

(a) March 12, 2011

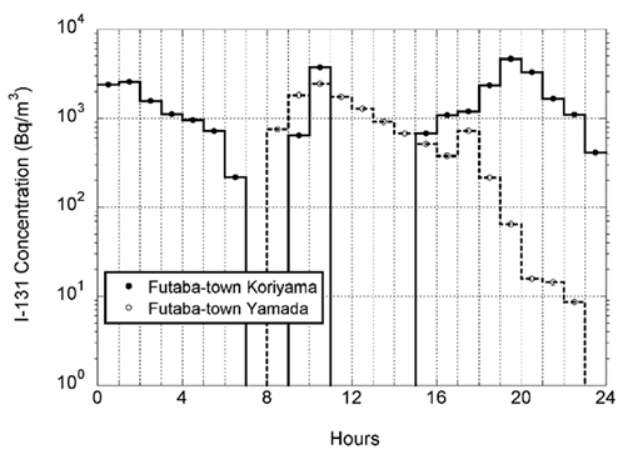

(b) Futaba-town, March 13, 2011

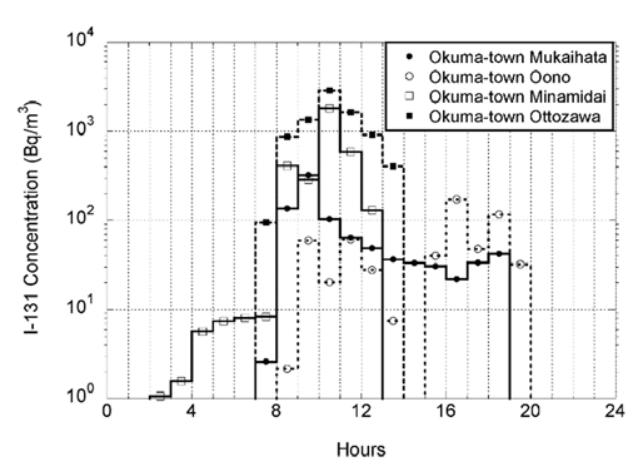

(c) Ookuma-town, March 13, 2011

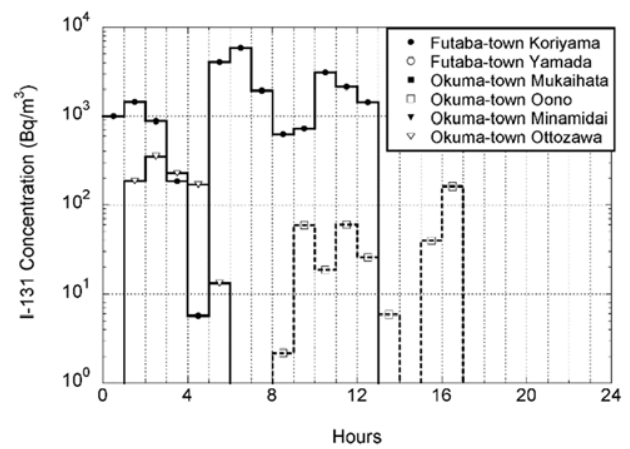

(d) March 14, 2011

Figure 9 Time histories of I-131 concentration in air at monitoring posts in Futaba Town and Okuma Town

(a) March 12, 2011, (b) Futaba Town, March 13, 2011, (c) Okuma Town, March 13, 2011, (d)March 14,2011

Town where data were available and an increase started as late as 11:00 on March 15 at Yamada in Futaba Town. These differences likely reflect weather conditions such as the direction of the wind. Although the locations and times are limited, the I-131 concentrations in air measured by sampling the air are shown on the website of the Ministry of Economy, Trade and Industry ${ }^{8}$. As the only result of measurements conducted in Futaba and Okuma towns, $12 \mathrm{~Bq} / \mathrm{m}^{3}$ was recorded between 8:37 and 8:47 at Ottozawa Chojahara in Okuma Town. The estimated value between 8:00 and 9:00 at the monitoring post at Ottozawa in Okuma Town is $16 \mathrm{~Bq} / \mathrm{m}^{3}$, nearly identical to the value recorded at Ottozawa Chojahara in Okuma Town.

When considering the influence of I-131 in the air, not only the I-131 concentration in air when a plume arrives but also the duration of the plume needs to be considered. Table 2 shows the average concentration in air as well as the time-integrated concentration in air during the estimated arrival of respective plumes. Figure 10 shows the locations of respective monitoring posts on the map ${ }^{9)}$ and the average concentration in air during the arrival of plumes to clarify the difference in the average concentration in air depending on the location of the $1 \mathrm{~F}$ plant and respective monitoring posts. The width of the bar graph indicates the duration for which the plume persisted and its area corresponds to the time-integrated concentration in air.

The I-131 emissions in the air estimated by Kobayashi, et al. ${ }^{10)}$ are also shown. The variation in the average concentration on March 12 differed markedly between Yamada and Koriyama in Futaba Town, both of which are at nearly the same distance from the 1F plant. Although an increase in the concentration corresponding to an increase in the estimated emission was 


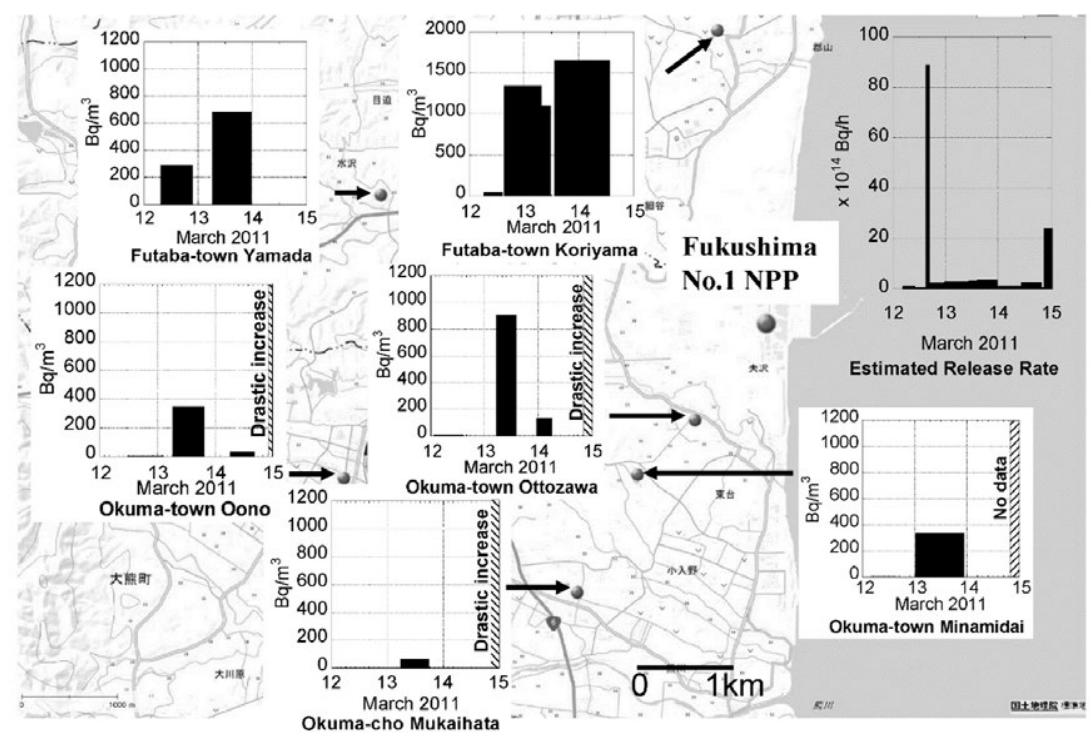

Figure 10 Average concentration of I-131 in air $\left(\mathrm{Bq} / \mathrm{m}^{3}\right)$ at monitoring posts in Futaba Town and Okuma Town together with I-131 estimated release rate $\left(10^{14} \mathrm{~Bq} / \mathrm{h}\right)^{10)}$

observed at Koriyama in Futaba Town, it was not clear at Yamada. This undoubtedly indicates that the average concentrations on March 13 differed depending on the distance and direction from the $1 \mathrm{~F}$ plant. For the monitoring posts where the analysis could not be conducted because of a drastic increase in emissions that occurred at midnight on March 14, "drastic increase" is displayed at and after the time of the occurrence of the increase and "no data" is displayed if no data are available. According to the figure, no increase occurred on March 14 at Yamada and Koriyama in Futaba Town.

\section{I-131 in the Air during March}

Figures 11-13 show the time history of the I-131 concentration in air at Shoukan in Naraha Town and Futatunuma in Hirono Town where the data obtained until 24:00 on March 31 were available and at Momijiyama in Fukushima City where data obtained until 18:00 on March 21 were available. Because of an increase in the count rates caused by the I-131 deposited in the surrounding areas as a result of the arrival of plumes, the detectable lowest detection concentration increases when the method of estimating the arrival of plumes from the time series shows a variation in peak count rates. When the error in determining a net count rate is $\sigma$ (cps), it is assumed that an increase in peak count rate can be detected in the event of a change of $3 \sigma$ or greater. Because the conversion factor of I-131 from the peak count rate to the concentration in air used in the analysis performed at the monitoring posts in Fukushima was $0.0524 \mathrm{cps}$ per $\mathrm{Bq} / \mathrm{m}^{3}$, the detection concentration limit $D_{\text {limit }}$ becomes

$$
D_{\text {limit }}\left(B q / m^{3}\right)=\frac{3 \sigma}{0.0524}
$$

Figures 11-13 also show the detection concentration limits obtained using equation (2).

Although a concentration in air comparable to the concentration measured on March 15 was observed from March 20 to 22 at Shoukan in Naraha Town, no corresponding increase 


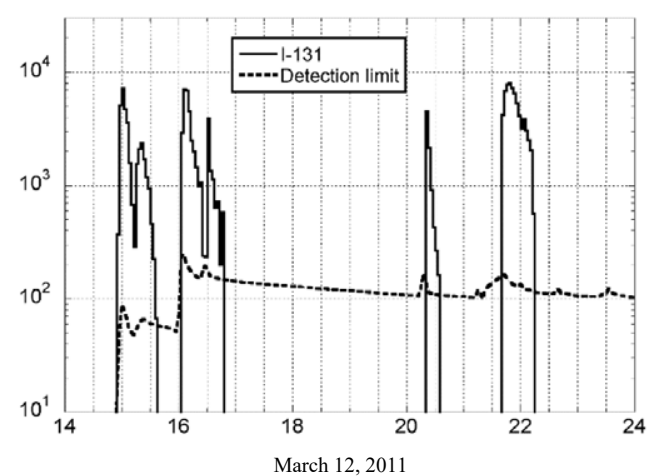

Figure 11 Time histories of I-131 concentration in air at Naraha Town Shoukan

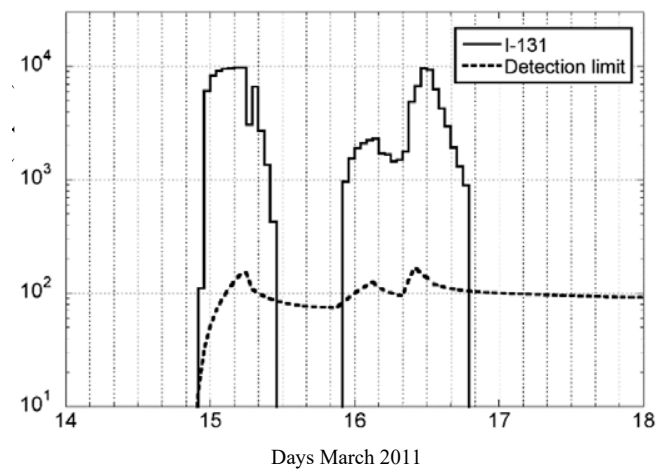

Figure 12 Time histories of I-131 concentration in air at Hirono Town Futatunuma

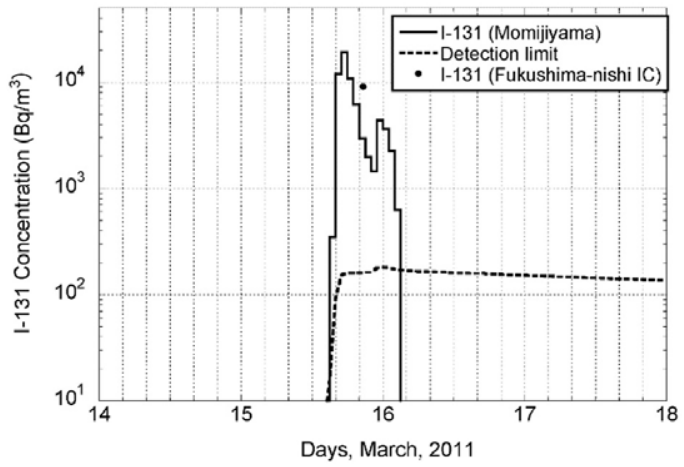

Figure 13 Time histories of I-131 concentration in air at Fukushima City Momijiyama together with estimated concentration at Fukushima-nishi IC obtained with the same method described in Ref. 11 using the $\mathrm{LaBr}_{3}$ pulse height distribution

was seen in the other two areas. In all three areas, no arrival of plumes containing I-131 at a concentration higher than the detection limit occurred on or after March 23. Figure 13 also shows the estimated I-131 concentration in air at Fukushima Nishi IC (4 km from Momijiyama in Fukushima City) determined using the pulse height distribution ${ }^{5)}$ of $\mathrm{LaBr}_{3}$ obtained with the same method as that described in reference 11. Considering that the values based on the 


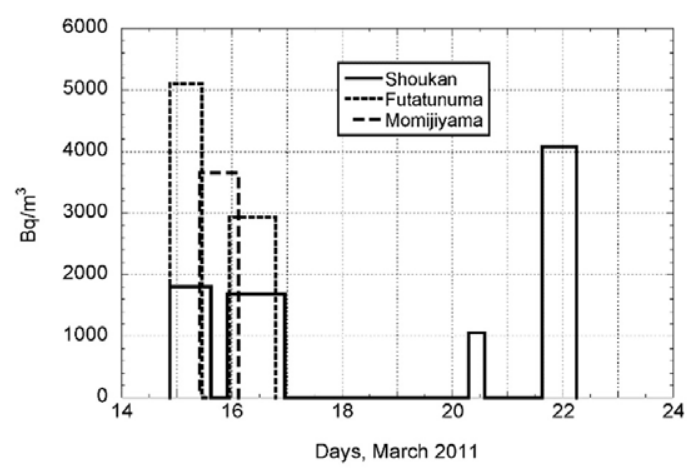

Figure 14 Comparison of average concentration of I-131 in air between Naraha Town Shoukan, Hirono Town Futatunuma and Fukushima City Momijiyama.

measurement using $\mathrm{LaBr}_{3}$ includes the impact of deposition and the concentration in air may be overestimated, it can be stated that the estimated values at Fukushima Nishi IC are the concentrations that correspond to the results obtained in this study.

Table 3 shows the average concentration in air and the time-integrated concentration in air during the arrival of plumes. Figure 14 shows a comparison of the average concentration in air among three locations. The 1F plant is $14.2 \mathrm{~km}$ from Shoukan in Naraha Town, $21.4 \mathrm{~km}$ from Futatunuma in Hirono Town, and $61.3 \mathrm{~km}$ from Momijiyama in Fukushima City. The times at which the I-131 concentration reached its maximum level because of the plumes that arrived between midnight on March 14 and midnight on March 15 are 0:00-1:00 on March 15 at Shoukan in Naraha Town, 5:00-6:00 on March 15 at Futatunuma in Hirono Town, and 17:00-18:00 on March 15 at Momijiyama in Fukushima City; the concentrations at these times were 7,220, 9,790 , and $19,100 \mathrm{~Bq} / \mathrm{m}^{3}$, respectively. Although the time-integrated concentration in air is important when considering the impact on internal exposure, as Table 3 shows, the time-integrated concentrations in air obtained by 24:00 on March 16 at Shoukan in Naraha Town and Momijiyama in Fukushima City were nearly the same, and that observed at Futatunuma in Hirono Town was approximately twice as high as those obtained at the other two locations. As described in Chapter II Section 3, because it would appear that the results obtained at Shoukan in Naraha Town between midnight on March 15 and March 16 underestimated the peak count rates around the time at which the peak count rates reached their maximum levels, the concentration in air may have been underestimated.

\section{Comparison with the Estimated Values Described in UNSCEAR ANNEX A ${ }^{3)}$}

UNSCEAR 2013 ANNEX A (hereinafter referred to as "UNSCEAR") includes Table B10 which shows the time-integrated I-131 concentrations in air at several locations. These concentrations were obtained using the estimated values of the time-dependent I-131 emissions from the $1 \mathrm{~F}$ plant as well as the atmospheric dispersion models. The time-integrated concentrations in air shown in the table were estimated using the methods employed by the U.S. National Oceanic and Atmospheric Administration - Global Data Assimilation System (NOAA-GDAS) and Institute for Radiological Protection and Nuclear Safety-European Centre for Medium Range Weather Forecasting (IRSN-ECMWF). The time-dependent emissions estimated by Terada, et al. ${ }^{12)}$ were used in NOAA-GDAS and those estimated by Saunier, et al. ${ }^{13)}$ were used in IRSN-ECMWF. They both estimated the emissions based on the measured radiation 
Table 4 Comparison of time-integrated concentration of I-131 in air between the results obtained in this study and estimated in UNSCEAR 2013 ANNEX A $^{3)}$

\begin{tabular}{|c|c|c|c|c|c|c|}
\hline \multirow{3}{*}{ Location } & \multirow{2}{*}{\multicolumn{2}{|c|}{ Time period March, 2011}} & \multirow{3}{*}{$\begin{array}{l}\text { Distance from Fukushima } \\
\text { Daiichi Nuclear Power } \\
\text { Station }\end{array}$} & \multirow{3}{*}{ This work } & \multicolumn{2}{|l|}{$\mathrm{Bq} \mathrm{h} / \mathrm{m}^{3}$} \\
\hline & & & & & UNSCEAR 20 & 3 ANNEX-A ${ }^{3)}$ \\
\hline & $\begin{array}{c}\text { From } \\
\text { (dd hh: mm) }\end{array}$ & $\begin{array}{c}\text { To } \\
\text { (dd hh : mm) }\end{array}$ & & & NOAA-GDAS ${ }^{\text {a) }}$ & IRSN-ECMWF $^{\mathrm{b})}$ \\
\hline $\begin{array}{l}\text { Futaba-town } \\
\text { Yamada }\end{array}$ & \multirow{3}{*}{$11^{\text {th }} 21: 23$} & \multirow{3}{*}{$12^{\text {th }} 21: 00$} & WNW $4.1 \mathrm{~km}$ & 2,440 & & \\
\hline $\begin{array}{l}\text { Futaba-town } \\
\text { Koriyama }\end{array}$ & & & NNW 2.8 km & 5,240 & & \\
\hline Futaba-town & & & & & 23,300 & \\
\hline $\begin{array}{l}\text { Naraha-town } \\
\text { Shoukan }\end{array}$ & \multirow{3}{*}{$12^{\text {th }} 13: 00$} & \multirow{3}{*}{$16^{\text {th }} 15: 00$} & SSW $14.2 \mathrm{~km}$ & 69,100 & & \\
\hline $\begin{array}{l}\text { Hirono-town } \\
\text { Futatunuma }\end{array}$ & & & $\mathrm{S} 21.4 \mathrm{~km}$ & 137,000 & & \\
\hline Iwaki-city & & & $\mathrm{S} 42.5 \mathrm{~km}$ & & 61,100 & 30,600 \\
\hline $\begin{array}{l}\text { Fukushima-city } \\
\text { Momijiyama }\end{array}$ & \multirow{2}{*}{$12^{\text {th }} 8: 00$} & \multirow{2}{*}{$19^{\text {th }} 8: 00$} & NW 61.3 km & 65,700 & & \\
\hline $\begin{array}{l}\text { Kawamata } \\
\text { elementary school }\end{array}$ & & & NW 51.7 km & & 18,900 & 20,800 \\
\hline
\end{tabular}

levels, and UNSCEAR indicates that the estimated values obtained using this method have high uncertainty even if the radioactive concentration in air is used. The time-dependent measurements of the concentration in air associated with the accident that occurred at the $1 \mathrm{~F}$ plant were limited to the those obtained after March 15 in Ibaraki Prefecture (Tokai Village and Tsukuba City) and Chiba Prefecture (Chiba City), which are located far away from the 1F plant. Before March 15 and in other areas, the radioactivity density on the ground surface and the dose rate information obtained at monitoring posts were used. Because it is difficult to obtain the time history data of the I-131 concentration in air from the radioactivity density on the soil surface and the variation in dose rate does not correspond with the variation in the I-131 concentration in air, the estimation based on these data has a higher uncertainty than the estimation based on the radioactivity concentration in air. Although the estimations had high uncertainty, to the best of our knowledge, no data were available to which they could be directly compared. Therefore, we compared the time-integrated concentrations in air, obtained at the locations, which could be associated with monitoring posts, among those shown in Table B10, with the time-integrated concentrations in air obtained in this study. Table 4 shows the results ${ }^{c}$. The period subject to integration is as shown in Table B10, and the values obtained in this study are the integrated values for the same period.

In a comparison on the north side of the 1F plant from 21:23 on March 11, which was immediately after the accident, to 21:00 on March 12, the time-integrated concentration in air, which was measured in Futaba Town and described in UNSCEAR, was approximately 10 and 4 times greater than the that measured at Yamada and Koriyama in Futaba Town, respectively. In a comparison, on the south side of the 1F plant from 3:00 on March 13 to 15:00 on March 16, the time-integrated concentration in air measured at Futatunuma in Hirono Town was twice as high as that measured at Shoukan in Naraha Town. However, as previously described, the results obtained at Shoukan in Naraha Town may have been underestimated. The estimated values obtained in Iwaki City and described in UNSCEAR were one-half (NOAA-GDAS) or one-quarter (IRSN-ECMWF) of those obtained at Futatunuma. In a comparison on the northwest side of the 1F plant from 8:00 March 12 to 8:00 March 19, the time-integrated concentration in air

\footnotetext{
${ }^{\mathrm{c}}$ Table 4 shows the values obtained by converting Bq s/ $\mathrm{m}^{3}$ values described in UNSCEAR into Bq $\mathrm{h} / \mathrm{m}^{3}$ values.
} 
measured at Momijiyama in Fukushima City, $61.3 \mathrm{~km}$ from the 1F plant, was approximately three times higher than that measured at Kawamata Elementary School in Kawamata Town, $51.7 \mathrm{~km}$ from the $1 \mathrm{~F}$ plant, as described in UNSCEAR. As previously mentioned, the results obtained in this study correspond to the results described in the UNSCEAR in terms of order, but the relation between both results differs depending on the time and location.

Although there is some uncertainty in the time-integrated concentration in air as estimated in this study associated with the method used to determine the absolute I-131 concentration in air from the time history pulse height distribution ${ }^{\mathrm{d}}$, it is based on the time history of the concentration in air estimated from the actual pulse height distribution data of the $\mathrm{NaI}(\mathrm{Tl})$ detector. However, because it is assumed, in the calculation of the conversion factor from the peak count rate to concentration in air, that the I-131 contained in the plumes distributed from the ground surface to the plume heights is of a uniform concentration, there may be a large error at the monitoring posts near the $1 \mathrm{~F}$ plant. Because the time histories of the concentration in air are not described in UNSCEAR, it is impossible to compare them. However, the estimated values described in UNSCEAR are based on time-dependent emissions determined using the radioactivity density deposited on the ground as well as the dose rate information obtained at the monitoring posts. Therefore, the estimated values obtained in this study better reflect actual conditions at least at the monitoring posts $10 \mathrm{~km}$ or farther from the $1 \mathrm{~F}$ plant. It would appear that the information on the time history of the I-131 concentration in air obtained in Fukushima Prefecture including the area around the $1 \mathrm{~F}$ plant in this study is useful in improving the precision of the estimation of time-dependent emissions using radioactivity data.

\section{Conclusions}

We estimated the I-131 concentrations in air in areas around the monitoring posts during March 2011 using the pulse height distribution data of a $\mathrm{NaI}(\mathrm{Tl})$ detector obtained at the monitoring posts and disclosed on the website of Fukushima Prefecture. Because the count rates were much higher than is typical because of the influence of high-concentration radionuclides emitted as a result of the accident that occurred at the $1 \mathrm{~F}$ plant, we performed digit overflow and (live time) / (real time) corrections of the disclosed pulse height distribution before using the data in the analysis. In addition, when a discontinuous tendency was observed in the time series variation in the peak count rates of I-131 because of the difference in the composition of radionuclides during the arrival of plumes, we interpolated the data after checking the pulse height distribution to avoid discontinuous variation. These corrections caused some uncertainty in the results obtained in this study, but it was necessary to make use of limited information.

The results obtained in this study are the first on the I-131 concentration in air continuously measured at fixed locations in Fukushima Prefecture during March 2011. In the areas near the $1 \mathrm{~F}$ plant, the results showed that while the plume mainly moved to the north on March 12, it moved in various directions on March 13, although data were limited to before the massive emission on March 15. We could confirm that no plume arrived before March 15 at Shoukan in Naraha Town, Futatunuma in Hirono Town, and Momijiyama in Fukushima City, where we could analyze the data obtained throughout nearly the whole of March. The plumes mainly arrived on March 15 and 16 and no plume containing a high-concentration of I-131 arrived at

\footnotetext{
${ }^{\mathrm{d}}$ As a result of comparing the estimated values to the air monitoring results concerning the time-integrated concentration of I-131 in air based on the data used in ref. 1 the ratio between them was within a range of from 0.2 to 4 , depending on period and location of monitoring posts.
} 
Futatunuma and Momijiyama.

In this study, we compared the time-integrated I-131 concentrations in air measured at several locations with the concentrations obtained using the estimated time-dependent emissions from the $1 \mathrm{~F}$ plant described in UNSCEAR and atmospheric dispersion models. The results corresponded to the results described in UNSCEAR in terms of order, but the relation between both results differed depending on the time and location. The major factor in this difference was the high uncertainty in the time-dependent emissions estimated using the radioactivity measurements of UNSCEAR.

From the results of this study, we found that it was possible to obtain the time history of the I-131 concentration in air as information on the conditions of I-131 diffusion resulting from the accident if the pulse height distribution data obtained at the monitoring posts were available. It would appear that analyzing not only the data that were obtained in Fukushima Prefecture and used in this study but also the data obtained at various monitoring posts during March results in more information on the time-dependent I-131 radioactivity concentration in air being available. This also contributes to an improvement in the accuracy of the estimation of time-dependent emissions as well as the estimation of the evaluation of time-dependent I-131 concentrations in air at various locations using time-dependent emission and atmospheric dispersion models.

We could not have performed this study without the disclosure of numerical pulse height distribution data obtained at the monitoring posts by Fukushima Prefecture. We would like to express our deepest gratitude to the Fukushima Nuclear Power Center for their endeavors to process an enormous quantity of data to post on the website.

\section{References}

1) H. Hirayama, M. Kawasaki, H. Matsumura, T. Ohkura, Y. Namito, T. Sanami, M. Taki, T. Oishi, M. Yoshizawa, "Estimation of I-131 concentration by using time history of pulse height distribution at monitoring post and detector response for radionuclide in plume," Trans. At. Energy Soc. Jpn., 13, 119126 (2014). [in Japanese]

2) http://www.atom-moc.pref.fukushima.jp/monitoring/monitoring201103/201103_mpdata.html, 2014.10.14 final confirmation.

3) UNSCEAR 2013 ANNEX A, Levels and Effects of Radiation Exposure due to the Nuclear Accident after the 2011 Great East-Japan Earthquake and Tsunami, United Nations, New York, 2014.

4) http://www.pref.fukushima.lg.jp/sec_file/monitoring/etc/post5-20120921.pdf, 2014.10 .14 final confirmation.

5) H. Matsumura, K. Saito, J. Ishioka, Y. Uwamino, "Diffusion of radioactive materials from Fukushima Daiichi Nuclear Power Station obtained by gamma-ray measurements on expressways," Trans. At. Energy Soc. Jpn., 10, 152-162 (2011). [in Japanese]

6) Y. Namito, H. Nakamura, A. Toyoda, K. Iijima, H. Iwase, S. Ban, H. Hirayama, "Transformation of a system consisting of plane isotropic source and unit sphere detector into a system consisting of point isotropic source and plane detector in Monte Carlo calculation," J. Nucl. Sci. Technol, 49, 167-172 (2012).

7) H. Hirayama, Y. Namito, A. F. Bielajew, S. J. Wilderman, W. R. Nelson, The EGS5 Code System, SLAC-R-730 (2005) and KEK Report 2005-8 (2005).

8) http://www.meti.go.jp/press/2011/06/20110603019/20110603019.html, 2014.10.14 final confirmation.

9) GSI Maps, Geospatial Information Authority of Japan.

10) T. Kobayashi, H. Nagai, M. Chino, H. Kawamura, "Source term estimation of atmospheric release due to the Fukushima Dai-ichi Nuclear Power Plant accident by atmospheric and oceanic dispersion simulations," J. Nucl. Sci. Technol., 50, 255-264 (2013).

11) H. Hirayama, H. Matsumura, Y. Namito, T. Sanami, "Estimation of radionuclide concentration in plume using pulse height distribution measured by $\mathrm{LaBr}_{3}$ scintillation detector and its response to radionuclides in plume calculated with egs5," Trans. At. Energy Soc. Jpn., 12, 304-310 (2012). [in Japanese]

12) H. Terada, G. Katata, M. Chino et al., "Atmospheric discharge and dispersion of radionuclides during the 
Fukushima Dai-ichi Nuclear Power Plant accident. Part II: verification of the source term and analysis of regional-scale atmospheric dispersion," J. Environ. Radioact., 112, 141-154 (2012).

13) O. Saunier, A. Mathieu, D. Didier et al., "An inverse modeling method to assess the source term of the Fukushima Nuclear Power Plant accident using gamma dose rate observations," Atmos. Chem. Phys., 13 [22], 11403-11421 (2013) 